\title{
PROSPECTIVE STUDY OF CHILDREN AND ADOLESCENTS WITH CEREBRAL PALSY TREATED WITH BOTULINUM TOXIN TYPE A: COMPARISON BETWEEN CLINICAL EVALUATION AND QUALITY OF LIFE (ABSTRACT)*. DISSERTATION. CURITIBA, 2007.
}

\section{DANIELLE CALDAS BUFARA RODRIGUES**}

Introduction: Cerebral palsy (CP) is the most common childhood physical disability, causing motor and functional limitation. Multidisciplinary treatment teams should be offered according to the needs of each patient to provide continuously updated global treatment care. Evaluation of results in a systematized way can be done us- ing specific clinical scales and the quality of life (QL) questionnaires.

Objective: To evaluate the QL among patients with $\mathrm{CP}$ using botulinum toxin type A (BTA) and to correlate these results with the clinical scales.

Casuistics: Parents and/or caregivers of children and ad- 
olescents with diagnosis of $\mathrm{CP}$ that use BTA during the time of clinical and QL evaluations at the AEP-CENEPHC-UFPR.

Method: Two questionnaires of QL, the Pediatrics Outcomes Data Collection Instrument (PODCI) and Caregiver Questionnaire (CQ), and clinical evaluation (CE), by Ashworth Scale, Functional Classification, Upper limb Physician's Rating Scale (UPRS), Physician Rating Scale (PRS) of dynamic gait pattern during active walking, Gross Motor Function Classification System (GMFCS) and Manual Ability Classification System (MACS). Questionnaires and CE were obtained at two moments in the whole study population with a mean interval of approximately one year moment before and after use of BTA.

Results: There were 57 participants at a mean interval of 13.8 months among the two moments of the study. The treatment with BTA brought clinical improvement seen in the Ashworth scale $(p=0.01)$, UPRS ( $p=0.03)$, Functional Classification, GMFCS and MACS (interval of $95 \%$ for the percentile of improvement). QL showed improvement in the comfort dimension of $C Q(p=0.06)$ and of the POD-
$\mathrm{Cl}$ dimensions: upper extremity and physical function $(p<0.001)$, transfers and basic mobility $(p=0.02)$ and global function and symptoms $(p=0.03)$. Clinical evaluation presented correlation between them and the QL. Children which age were below 78 months presented better results with the use of BTA. Children of caregivers with lower education degree and smaller per capita income presented worse results, observed by GMFCS $(p=0.004)$, comfort dimension $(p=0.008)$ and global score $(p=0.05)$ of $C Q$, and transfers and basic mobility dimension $(p=0.02)$ of PODCl. The presence of epilepsy and mental retardation occurred in a third of the sample with worse result to the treatment.

Conclusion: Clinical evaluation and QL were sensitive to detect changes after treatment and had correlation between them. BTA propitiated spasticity reduction; better results in the functional capacity and in the patients' QL. Younger patients with point of cut at 78 months were who got better results with BTA.

Key words: cerebral palsy, quality of life, botulinum toxin tipe A, spasticity.

*Estudo prospectivo de crianças e adolescentes com paralisia cerebral tratadas com toxina botulínica do tipo A: comparação entre avaliação clínica
e qualidade de vida (Resumo). Dissertação de Mestrado, Universidade Federal do Paraná (Área: Neuropediatria). Orientadora: Lúcia Helena Coutinho dos Santos.

Address: AEP-CENEP-HC-UFPR (Ambulatório de Espasticidade do Centro de Neuropediatria do Hospital de Clínicas da Universidade Federal do Paraná) - Rua Floriano Essenfelder 81 - 80060-270 Curitiba PR - Brasil. 